\title{
Health Service Delivery as a Research Agenda
}

For any company or organization, its service delivery mirrors its effectiveness in attaining its goals. For a health care institution, this is health service delivery. Why should health service delivery be a priority of any health care institution or organization?

The World Health Organization (WHO) talks about improving the quality of patient-centered health service as the road to achieving universal health coverage and the Sustained Development Goals (SDGs). ${ }^{1}$ The US Agency for International Development (USAID) embarked on ASSIST, Applying Science to Strengthen and Improve Systems, a fiveyear project designed to improve health and social services in USAID-assisted countries. ${ }^{2}$

It is imperative that health service delivery is designed in such a way that it is based on the best scientific evidence for a particular disease, is made easily accessible, and one that follows a structure or system that will support its delivery.

The USAID further puts an even broader concept called governance for quality health care and service delivery. These include use of policy and strategies, effective regulation, engaging non-state actors, garnering political will, pursuing reliable data, culture of continuous improvement, promoting knowledge sharing, and linking financing to quality. ${ }^{2}$

Health service delivery as a research agenda, therefore, is not only confined to looking for treatment interventions based on the best evidence. It should also consider addressing access and availability of the health service, and the institutional architecture to support a quality health service or intervention. Defining of roles and responsibilities of personnel at various levels of care within the organization and the aligning of other resources necessary for delivery are vital parts of it also.

In the Philippines, the National Unified Health Research Agenda (NUHRA) came about as it reflects the health needs of the Filipinos. The NUHRA creates a template for health research in these specific areas in a 5-year scope. ${ }^{3}$

The Philippine General Hospital (PGH) has included health service delivery as one of its top research agenda. In the past 4 years that it has established such, many of the research outputs have addressed specific disease interventions, hospital processes, and personnel welfare and readiness. There are still, however, a lot of gaps and questions that remain to be addressed.

The papers on this fourth issue of the PGH for Acta Medica Philippina are diverse in scope but are all products of the authors' questions that needed addressing in order to improve delivery of care to the PGH patients. May the impact of the results of these research endeavors truly make a difference in the lives of the patients the National University Hospital serves.

\author{
Jean Anne B. Toral, MD, MSc \\ Coordinator for Research \\ Philippine General Hospital
}

\section{REFERENCES}

1. World Health Statistics 2016 Monitoring Health for the SDGs. ISBN 9789241565264.

2. Laird K, Tarantino L, Mennen T, Koon A. Governance to Improve the Quality of Health Services: A Research Agenda. January 2018.

3. Philippine National Health Research System, National Unified Health Research Agenda [Internet]. [cited 2021 Feb 5]. Available from: www. healthresearch.ph/index.php/nuhra1. 